\title{
Structural variations on the surface of metallic products at laser marking
}

\author{
D. A. Konchus, Post-graduate, Engineerl, 2 \\ E. I. Pryakhin, Dr. Eng., Prof., Head of Dept. of Material Science and Technology of Artefacts ${ }^{1}$, \\ e-mail: e.p.mazernbc@yandex.ru \\ A. V. Sivenkov, Cand. Eng., Associate Prof. 1
}

\author{
${ }^{1}$ St. Petersburg Mining University, St. Petersburg, Russia \\ 2ITMO University, St. Petersburg, Russia
}

\begin{abstract}
Laser marking of products and details is used more and more wide in different production areas, because it has undisputable advantages in comparison with other marking methods. Action of laser beam on the surface of marking product is the principal feature of laser marking. It is accompanied with local heating of this surface and its partial melting together with material evaporation from the surface contact point. Influence of laser impulse action on efficiency of marking on the surface of machine-building details is examined in this work. The samples of $08 \mathrm{Kh} 18 \mathrm{~N} 10$ steel were used as material. Marking was conducted by the system "MiniMarker 2-20A4", QR code was used as a marker. The marking parameters were optimized via the method of experimental design. The optimal marking procedure for getting maximal contrast of QR code was calculated and experimentally confirmed. Steel surface roughness was analyzed using profilograms. Contrasting effect and roughness of code were determined and relationship between these parameters was revealed. Contrast effect of marking increases with elevation of roughness. However, roughness has less input in increase of contrast effect comparing with colour hue of the surface of an information block and substrate. The link between surface roughness and contrast effect of marking is shown. Possibility of contrast effect assessment of QR code using profilometer is suggested.

Key words: laser marking, experimental design, QR code, surface properties, contrast effect, roughness, profilometer. DOI: $10.17580 /$ cisisr.2021.02.18
\end{abstract}

\section{Introduction}

There are many various methods for marking application For example, labels which are glued on package or directly on products, can be manufactured by printing. The labels which have the form of carrier are often molten to mark plastic products $[1,2]$. However, such methods are not reliable, because applied marking is rubbing and damaging during product operation and can be replaced easily. Therefore, use of direct marking methods is required, when information is located just on the surface of finished product.

Embossing and stamping can be mentioned as such direct methods, but they are just out-of-date. Electrochemical marking is also considered as direct method, but the most demanded and up-to-date technique is now various engraving, e. g. laser engraving [3, 4]. Efficiency of laser engraving use is determined by its workability, by high marking speed of products, by contactless operation, by stability and reliability of image, by suitability of apprehension and by possibility of control for legality of products using created electronic data bases [5, 6].

Action of laser emission on variation of the state of marking product is the main mechanism of laser marking. When laser emission effects on different materials (both metallic and non-metallic), local heating appears; partial melting and evaporation of material from the surface contact point [7]. If we move laser beam along the sample surface, we get any visible image presented by signs, pictures, letters and figures $[8,9]$. This research used QR codes as the image applied during marking; they are widely used for marking the finished products.
Processing surface has optical properties which are typical for the concrete material. So, laser effect on product surface leads to partial absorption of laser emission through definite depth of material and partial reflection [10]. Thereby there is definite relationship between absorbing and reflecting capacities of material and its optical properties.

To increase absorption coefficient and to decrease reflection coefficient, so-called substrate is applied by laser to the place of future marking. Thereby, dull surface of product is formed together with substrate, what provides better code scanning in comparison with lustrous metallic surface $[11,12]$. Surface relief also has the effect on scanning capacity.

The aim of this research was reveal of the relationship between laser marking parameters and contrasting effect of applied image, as well as influence of surface roughness of contrast effect of marking.

\section{Methods and materials}

In this research the image was applied on flat samples of cold-rolled sheet with thickness $1.5 \mathrm{~mm}$ and surface roughness (Ra) $0.112 \mu \mathrm{m}$ using fiber laser "MiniMarker 2-20A4" $[13,14]$. Stainless steel $08 \mathrm{Kh} 18 \mathrm{~N} 10$ (chemical composition according to the GOST 5632-2014) was the material for pilot samples. QR code containing a little more than 300 signs of typescript text, with code dimensions $35 \times 35 \mathrm{~mm}$, was selected as the image for marking. Marking process was conducted via several passes to form two elements (substrate and code itself). To create the image which absolutely 
provides efficient QR code scanning, it is necessary to get this image with maximal contrast effect [15-17]; it is determined by correct selection of laser marking parameters. Thereby optimal parameters of marking application by laser device using experimental design method were determined in this work $[18,19]$. Contrast effect as a response function during experimental design was evaluated by the parameters of RGB additive model within Photoshop CC program; in this case the variation range was started from absolutely black colour (marked as 0 ) to absolutely white colour (marked as 255).

Optimization of laser marking parameters was conducted using fractional factorial experiment of $2^{7-3}$ kind with duplication in the central view [20].

3 levels of variation of the examined factors were selected in order to find out marking procedure which is corresponded to optimal one (Table 1).

Lineature means density of halftone image, number of lines per unit of image length $[4,9]$. Lower indexes $\mathrm{C}$ and $\mathrm{S}$ mean code and substrate respectively.

Variation range is calculated via the formula

$$
\Delta=\frac{\max -\min }{2},
$$

16 experiments were conducted in this work instead of 128 , it makes $1 / 8$ of replicate from the full factorial experiment. This replicate can be obtained via replacement of three interaction effects for examined factors by the new factors $X_{5}, X_{6}, X_{7}$.

Contrast effect $\mathrm{K}$ was calculated after measuring RGB parameters for substrate $\left(B_{S}\right)$ and code $\left(B_{C}\right)$ via the following formula:

$$
K=\frac{B_{S}-B_{C}}{B_{S}} .
$$

Processing material is characterized by any surface relief and colour. This relief is varying during marking, as well as colour brightness; respectively, material contrast effect and scanning ability of applied bar code are also varying. As soon as the code contrast effect depends on parameter of marking surface roughness, the roughness gradient parameter was calculated in this work:

$$
\Delta=R_{\text {a code }}-R_{\text {a subs }}
$$

where $\mathrm{R}_{\mathrm{a}}$ - is arithmetical mean deviation of evaluating shape, which determines positive values within the basic length of $\mathrm{Z}(\mathrm{x})$ ordinates. Roughness parameter of white field (i. e. substrate) and image applied on steel ( $Q R$ code) were determined using profilometer in this research. The profilogram was measured from this place using Mitutoyo Surftest SJ-210 profilometer. The length of line, which is made perpendicular to lineature, was used for determination of roughness parameter.

\section{Experimental part}

21 experiments were conducted in correspondence with the plan of fractional factorial investigation, part of the results are presented on the Fig. 1. It can be seen that the obtained OR code images are characterized by various contrast

\begin{tabular}{|c|c|c|c|c|c|c|c|c|c|}
\hline \multicolumn{3}{|c|}{ Factor } & \multirow{3}{*}{$\begin{array}{l}\text { Variation } \\
\text { range }(\Delta)\end{array}$} & \multicolumn{6}{|c|}{ Levels } \\
\hline \multirow{2}{*}{ Variable } & \multirow{2}{*}{ Title } & \multirow{2}{*}{ Designa-tion } & & \multicolumn{2}{|c|}{ Minimal } & \multicolumn{2}{|c|}{ Basic } & \multicolumn{2}{|c|}{ Maximal } \\
\hline & & & & Value & Code & Value & Code & Value & Code \\
\hline$X_{1}$ & Frequency & $\mathrm{n}$ & 20 & 60 & -1 & 80 & 0 & 100 & 1 \\
\hline$X_{4}$ & Capacity & $\mathrm{P}$ & 10 & 20 & -1 & 30 & 0 & 40 & 1 \\
\hline$x_{7}$ & $\begin{array}{l}\text { Duration } \\
\text { of impulse }\end{array}$ & $t$ & 75 & 50 & -1 & 125 & 0 & 200 & 1 \\
\hline$x_{3}$ & Speed & $\mathrm{V}_{\mathrm{c}}$ & 5 & 5 & -1 & 10 & 0 & 15 & 1 \\
\hline$x_{6}$ & Lineature & $\mathrm{Ipi}_{\mathrm{C}}$ & 15 & 20 & -1 & 35 & 0 & 50 & 1 \\
\hline$X_{2}$ & Speed & $\mathrm{V}_{\mathrm{S}}$ & 150 & 450 & -1 & 600 & 0 & 750 & 1 \\
\hline$X_{5}$ & Lineature & $\mathrm{Lpi}_{\mathrm{S}}$ & 15 & 60 & -1 & 75 & 0 & 90 & 1 \\
\hline
\end{tabular}
effect, which is determined by the complex of different values of parameters of laser action on the samples surface.
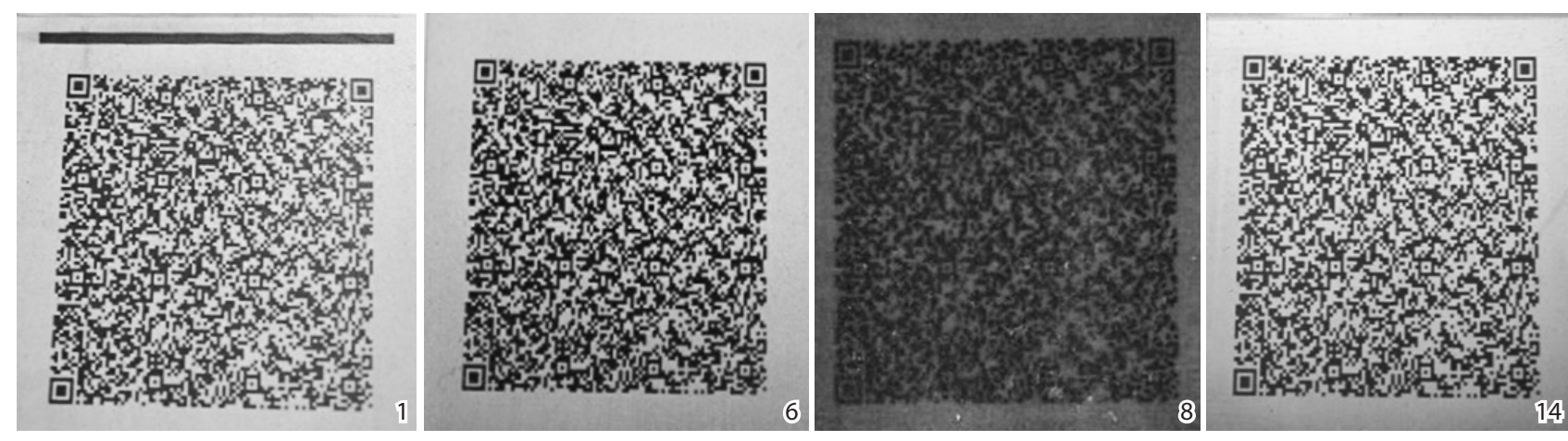

Fig. 1. Examples of samples with $Q R$ code applied according to the experimental parameters 
To evaluate image expression in electronic devices, RGB additive colour model is used; it describes the method and the results of colour coding [21, 22]. Measuring of contract effect in this work was carried out by parameters of such model. Obtained results after analysis of all experimental samples were displayed in the Table 2.

The reference $\mathrm{QR}$ code was printed on the paper with density $80 \mathrm{~g} / \mathrm{m}^{2}$; printing density of the laser printer was $1200 \mathrm{dpi}$, contrast effect of such code made $83 \%$.

Microstructure of samples was studied in three areas of applied QR code. The boundaries between the areas of substrate application on steel, of transition from substrate to code were pictured with 5 times magnification, while the boundary of transition from substrate to code was also pictured with 20 times magnification. After examination, all samples were classified in 4 groups:

- samples without "marking - sub-

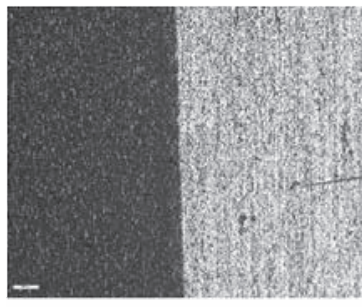

$a$

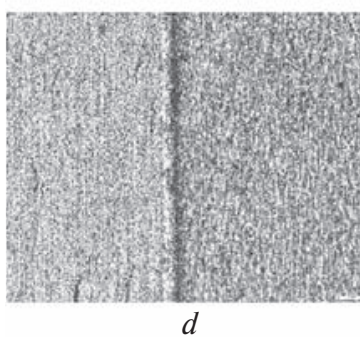

Fig. 2. Micro-relief of the samples No. 4 and No. 2 after marking application: $a$ - sample No. 4, boundary "steel - substrate", magnification $\times 5 ; b-$ sample No. 4, boundary "substrate - code", magnification $\times 5$; $c$ - sample No. 4 , boundary "substrate - code", magnification $\times 20$; $d$ - sample No. 2, boundary "steel - substrate", magnification $\times 5$; $e$ - sample No. 2, boundary "substrate - code", magnification $\times 5$; $f$ - sample No. 2 , boundary "substrate - code", magnification $\times 20$ strate" boundary;

- samples with lineature of marking application $50 \mathrm{l} / \mathrm{mm}$; - samples with lineature of marking application $201 / \mathrm{mm}$; - samples with applied marking according to parameters of central view.

It can be seen from the Table 2 that minimal contrast of applied marking was observed for two samples (No. 3 and No. 8),

\begin{tabular}{|c|c|c|c|c|c|c|c|}
\hline \multicolumn{6}{|c|}{ Table 2. Contract effect of examined samples } \\
\hline $\begin{array}{c}\text { No. of } \\
\text { sample }\end{array}$ & $\begin{array}{c}\text { RGB of } \\
\text { substrate }\end{array}$ & $\begin{array}{c}\text { RGB of } \\
\text { code }\end{array}$ & $\begin{array}{c}\text { Contrast } \\
\text { effect }\end{array}$ & $\begin{array}{c}\text { No. of } \\
\text { sample }\end{array}$ & $\begin{array}{c}\text { RGB of } \\
\text { substrate }\end{array}$ & $\begin{array}{c}\text { RGB of } \\
\text { code }\end{array}$ & $\begin{array}{c}\text { Contrast } \\
\text { effect }\end{array}$ \\
\hline 1 & 144 & 53 & 0,63 & 9 & 164 & 52 & 0,68 \\
\hline 2 & 160 & 47 & 0,71 & 10 & 194 & 71 & 0,63 \\
\hline 3 & 87 & 59 & 0,32 & 11 & 211 & 53 & 0,75 \\
\hline 4 & 138 & 23 & 0,83 & 12 & 94 & 40 & 0,57 \\
\hline 5 & 169 & 54 & 0,68 & 13 & 188 & 40 & 0,79 \\
\hline 6 & 138 & 26 & 0,81 & 14 & 211 & 76 & 0,64 \\
\hline 7 & 135 & 31 & 0,77 & 15 & 211 & 39 & 0,82 \\
\hline 8 & 75 & 43 & 0,43 & 16 & 105 & 50 & 0,52 \\
\hline \hline a & 150 & 37 & 0,75 & $d$ & 186 & 48 & 0,74 \\
\hline & 152 & 34 & 0,78 & $\mathrm{e}$ & 184 & 44 & 0,76 \\
\hline
\end{tabular}

which are related to the $1^{\text {st }}$ group. Metallographic examination of the surface didn't reveal the boundary "substrate - code" for these samples. Their scanning ability is absent.

The samples Nos. 1, 2, 4, 6, 12, 13 and 15 can be considered for the 2nd group. They are characterized with slight overlapping of marking lines (Fig. $2 a, b, c$ ), what testifies about incorrect selection of code application lineature. However, the samples have straight and distinct lines of substrate application (Fig. $2 d, e, f$ ). The maximal contract is observed in this group, despite overlapping of adjacent laser passes.

The samples Nos. 5, 7, 9, 10, 11, 14 and 16 are classified for the 3 rd group (Fig. 3). These samples have optimal value of marking application lineature. It can be concluded on the base of laser beam print image in the beginning of each laser pass. The prints of each pass have distinct boundaries and are not crossing with each other. The sample No. 14 has the most straight lines of substrate application. QR code of the samples Nos. 5, 9, 10 and 11 is scanning without delay, while the sample No. 16 can't be scanned. Microstructure of the samples with applied marking according to parameters of central view is presented on the Fig. $3 d$, $e, f$.

All samples were subjected to laser processing according to parameters of central view. It is confirmed by laser beam print, which is the same for all 5 samples. Distinct transition lines of laser beam can be seen 


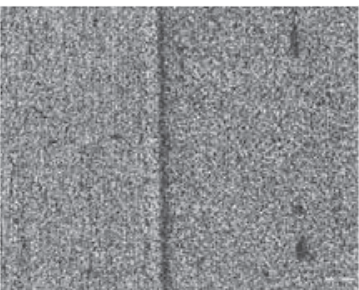

$a$

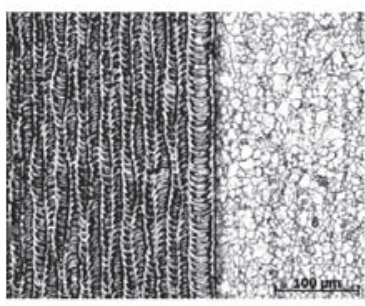

$d$

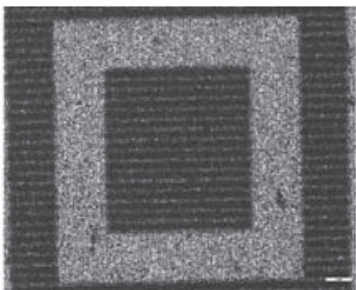

$b$

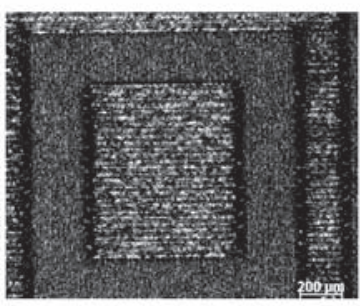

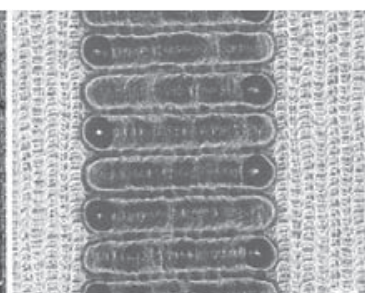

$c$

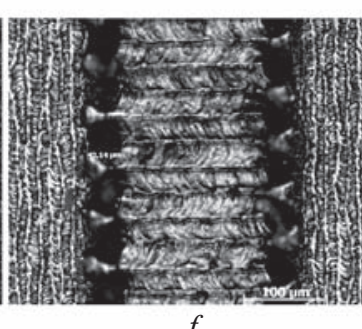

Fig. 3. Micro-relief of the samples No. 14 and No. 16 after marking application: $a$ - boundary "steel - substrate", magnification $\times 5 ; b$ - boundary "substrate - code", magnification $\times 5 ; c$ - boundary "substrate - code", magnification $\times 20$; $d$ - boundary "steel - substrate", magnification $\times 5$; $e$ - boundary "substrate - code", magnification $\times 5 ; f$ - boundary "substrate - code", magnification $\times 20$

on the Fig. $3 e$, what makes it possible to testify on correct lineature selection in marking process. Scanning of marking passes without any delays for all samples of this group.

As a result, the equation of response function was composed on the base of all obtained data

$\mathrm{Y}=0,661+0,065 X_{1}+0,026 X_{2}-0,045 X_{4}-0,015 X_{5}+$ $+0,024 X_{6}+0,091 X_{7}$

Statistical importance of the equation coefficients was calculated according to the Student's criterion for obtained values of contrast effect. Adequacy checking of the model was conducted according to the Fisher's criterion.

To determine roughness influence, nine samples were selected - four samples from each of the $2^{\text {nd }}$ and $3^{\text {rd }}$ groups, and one sample from the $1^{\text {st }}$ group. The roughness parameters $\left(R_{a}\right)$ of information block and substrate, as well as roughness gradient parameter $(\Delta)$, which were measured by profilometer, are presented in the Table 3.

\begin{tabular}{|c|c|c|c|}
\hline \multicolumn{4}{|c|}{$\begin{array}{l}\text { Table 3. Roughness parameters } \mathbf{R}_{\mathrm{a}} \text { and roughness gradient } \\
\text { parameters } \Delta\end{array}$} \\
\hline $\begin{array}{l}\text { No. of } \\
\text { sample }\end{array}$ & $\begin{array}{c}\text { Roughness of } \\
\text { substrate } \mathrm{R}_{\text {a subs }} \\
\mu \mathrm{m}\end{array}$ & $\begin{array}{c}\text { Roughness of } \\
\text { information block } \\
\mathrm{R}_{\mathrm{a} \text { code }}, \mu \mathrm{m}\end{array}$ & $\begin{array}{l}\text { Roughness } \\
\text { gradient } \Delta, \mu \mathrm{m}\end{array}$ \\
\hline 2 & 0.59 & 2.89 & 2.30 \\
\hline 3 & 0.57 & 0.46 & -0.11 \\
\hline 4 & 0.54 & 3.00 & 2.46 \\
\hline 6 & 0.55 & 4.83 & 4.28 \\
\hline 9 & 0.56 & 2.21 & 1.66 \\
\hline 11 & 0.53 & 3.67 & 3.14 \\
\hline 14 & 0.58 & 2.00 & 1.42 \\
\hline 15 & 0.57 & 8.57 & 8.00 \\
\hline 16 & 0.57 & 1.32 & 0.75 \\
\hline
\end{tabular}

The obtained profilogram of the examined sample is presented on the Fig. 4.

The results of examination of $Q R$ code microstructure allowed to reveal furrows which appeared after laser beam processing of the sample surface (see Fig. 2 and 3). Width of this furrow corresponds to diameter of laser spot. Formed distance between the furrows can vary depending on parameters of laser action, especially on lineature. These distances between the furrows have negative influence on the contrast effect of applied code, because appearance of intervals between laser passes increases surface reflecting capacity in comparison with its absorbing capacity [25-27]. Lineature increase leads to rise of the contrast effect. Distribution of examining distances can be also observed on profilograms, thereby investigation of distribution features for furrows using profilograms can characterize the marker scanning ability, as well as examination of surface structure after marking using microscope.

Power intensity of consequent impulses has influence on material surface relief [28, 29]. Intensity rise leads to increase of wave relief height and surface melting degree. High intensity during extremely small action time provided creation of small wave relief of steel surface for the sample No. 12. Absence of substantial roughness is confirmed by the profilogram (Fig. 5).

Increase of laser emission speed leads to strong enlargement of ledges of furrows after laser beam passing in the conditions of high emission intensities. It is caused by the fact, that molten metal part has not enough time to be distributed via the process of thermocapillary instability. Increase of furrow ledges and appearance of burrs enable rise of absorbing capacity of the code information block.

Analysis of profilograms displayed that location of roughness peaks corresponds to burrs in the area of emission flow action, thereby use of profilometer for examination of complicated surface relief after laser action of the surface is applicable.

Contrast effect parameters $\mathrm{K}$ and roughness gradient parameters between the information block and substrate $\Delta$, which were obtained during the research, are presented in the Table 4.

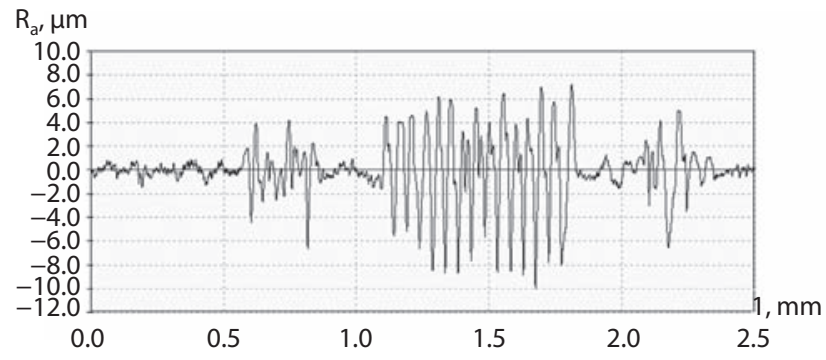

Fig. 4. Profilogram of the sample No. 4 


\begin{tabular}{|c|c|c|}
\hline \multicolumn{3}{|l}{$\begin{array}{l}\text { Table 4. Contrast effect parameters } \mathbf{K} \text { and roughness gradient } \\
\text { parameters of code } \Delta\end{array}$} \\
\hline \multirow{2}{*}{ No. of sample } & Contrast effect & Roughness $\mathrm{R}_{\mathrm{a}}$ \\
\cline { 2 - 3 } & Parameter $\mathrm{K}, \%$ & Parameter $\Delta, \mu \mathrm{m}$ \\
\hline 3 & 32 & -0.11 \\
\hline 16 & 52 & 0.75 \\
\hline 14 & 64 & 1.42 \\
\hline 9 & 68 & 1.66 \\
\hline 2 & 71 & 2.30 \\
\hline 11 & 75 & 2.46 \\
\hline 6 & 81 & 3.14 \\
\hline 15 & 82 & 4.28 \\
\hline 4 & 83 & 8.00 \\
\hline
\end{tabular}

It can be concluded on the base of the data obtained during the research, that contrast effect of the sample processed by laser is mainly connected with its roughness.

If the contrast effect parameter is distributed ascending, then roughness gradient parameter for the samples Nos. 2, $3,9,14$ and 16 is located in the same order.

Remaining samples have maximal parameters, both in roughness gradient and in contrast effect. The samples Nos. 4, 6 and 15 have larger contrast effect than the code applied on the white paper leaf by printer; it means assured and quick QR code scanning from these samples.

Variations of light and dark degrees or lightness and saturation (characterized by brightness) as well as colour tone are considered as the main colour parameters.

As soon as surface roughness increases, absorbing capacity of solid bodies also rises.

Visual macroanalysis displayed that colour saturation parameter is minimal for the samples No. 3 and No. 16, which are characterized by low roughness owing to small action time. Colour tone and saturation are unsatisfied in general, thereby these samples have minimal contrast effect.

Three samples Nos. 2, 5 and 9 have average contrast effect, and average roughness gradient parameter, their colour tone is brown-red.

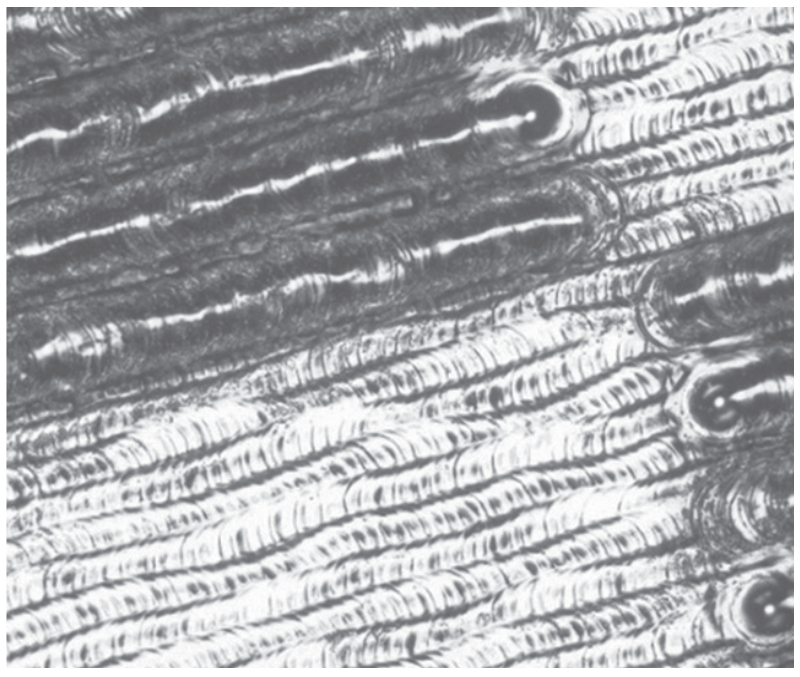

Fig. 5. Surface relief and profilogram of the sample No. 16
Remaining samples were characterized by saturated contrast effect during average time period, owing to the part of dark colour tone, which increases with enlargement of power density. However, marking with high roughness parameters is not the most contrast. It is connected with colour tone. As soon as molten areas are located on the boundaries of information blocks, RGB parameter decreases and, respectively, contrast effect of applied marking also decreases for high RGB parameters of the code itself.

When marking the sample No. 4 at high action capacity and during average action time, material evaporation occurred with small melting. As a result, the most high part of dark colour tone was formed together with distinct boundaries of blocks and high saturation, thereby maximal scanning ability was observed.

\section{Conclusions}

Analysis of surface microstructure makes it possible to evaluate, if the marking parameters are chosen correctly or no. Distinct lines of laser emission passing display correct selection of marking lineature. Analysis of the model has shown that duration of an impulse, frequency and power of laser emission are the most important factors. At the same time, speed of code and substrate application as well as their lineature have no substantial effect on the contrast of applied image or are not so important. Interaction of speed and frequency of code and substrate application, as well as frequency and power have influence on contrast effect value.

Maximal contrast of applied marking made $83 \%$, what corresponds to the contrast effect during printing on a white paper sheet.

The conducted analysis of surface roughness for marked steel was done using profilograms and microstructure pictures, and it showed possibility of determination of various surface characteristics and defects.

After marking, steel surface is characterized by furrow structure. Furrows of information code have width $30 \mu \mathrm{m}$, melting depth $60 \mu \mathrm{m}$ and distance between furrows $10 \mu \mathrm{m}$

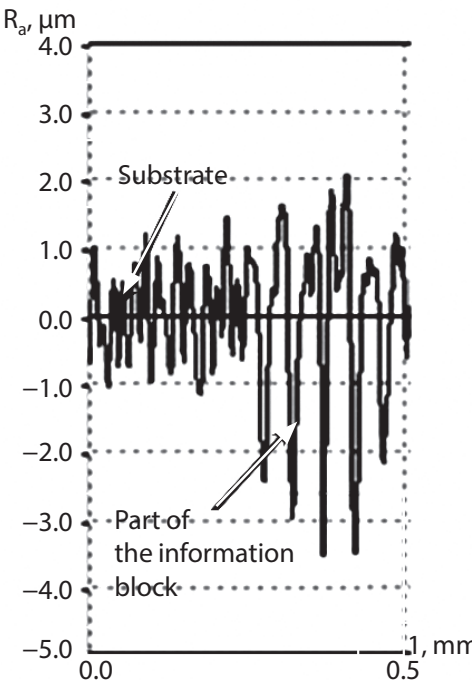
which varies depending on lineature and power density of laser emission. Height of ledges along furrow edges of information block varies from $0.5 \mu \mathrm{m}$ (for samples with average power density and small action time) to $16 \mu \mathrm{m}$, due to passing of different physical processes.

Code contrast effect and roughness were determined and relationship between these two parameters was revealed; marking contrast effect increases with rise of roughness. When substrate roughness 
parameter $\left(R_{a}\right)$ is within the range $0.54-0.57 \mu \mathrm{m}$, and code roughness parameter $\left(R_{a}\right)$ is more than $3 \mu \mathrm{m}$, the best contrast effect characteristics of applied image are observed. However, roughness has less input in the contrast effect rise in comparison with coloured tone of the information block and substrate surface.

The results of the research can be used for increase of QR code contrast effect, providing improvement of laser marking technology with saving of economical efficiency. The obtained results of determination of laser marking optimal parameters allow to exclude additional calculations, using obtained data for required tasks, to achieve maximal contrast.

The reported study was financially supported by the Ministry of Science and Higher Education of the Russian Federation, research agreement No. 075-11-2019-066 of 22.11.2019, project title "Development of high-tech production of equipment and technologies for laser coding of transported goods and their optical identification for the implementation in modern material flow management systems" (within the framework of decree of the Government of the Russian Federation, No. 218 of 09.04.2010).

\section{REFERENCES}

1. Ignatov A. G. Laser technologies: tasks and solutions. RITM Mashinostroenie. 2018. No. 6. pp. 30-33.

2. Yurevich V. I. Optics of laser technological assemblies: motion to perfectness. RITM Mashinostroenie. 2019. No. 3. pp. 14-19.

3. Wang G., Wang H., Zhang X., Li Y. Research on the Trajectory Control Method for Laser Marking. Key Engineering Materials. 2013. Vol. 579-580 KEM. pp. 614-617. DOI: 10.4028/www.scientific.net/KEM.579-580.614.

4. Larionova E. V., Ganzulenko O. Yu., Petkova A. P. Marking technology for serial products from metallic and polymer materials via impulse laser emission. Scientific week of St. Petersburg Polytechnic University: Collection of scientific works. 2014. pp. 178-181.

5. Maksarov V. V., Leonidov P. V. Simulation and management of dynamic properties in technological systems. Zapiski Gornogo instituta. 2014. Vol. 209. pp. 71-77.

6. Khalimonenko A. D., Pompeev K. P., Timofeev D. Yu. Dimensional analysis of the manufacturing processes of axisymmetric parts. IOP Conference Series: Materials Science and Engineering. 2019. Iss. 1. Vol. 1. pp. 1-6. DOI: 10.1088/1757-899X/560/1/012144.

7. Vasilyev O. S., Gornyi S. G. Technology of surface microstructures creation on sheet materials using fiber laser. Metalloobrabotka. 2016. No. 3 (93). pp. 20-25.

8. Petkova A. P., Ganzulenko O. Yu. Selection of steels composition in order to obtain the images with complete colour gamma on the surface of products during impulse laser emission. Zapiski Gornogo instituta. 2014. Vol. 209. pp. 216-219.

9. Larionova E. V., Khromova E. I. Features of transformation of graphic objects during preparation of patterns for laser treatment. Zapiski Gornogo instituta. 2014. Vol. 209. pp. 225-228.

10. Antonov D. N., Burtsev A. A., Butkovskiy O. Ya. Metal surface painting under the effect of impulse laser emission. Zhurnal tekhnicheskoy fiziki. 2014. Vol. 84. Iss. 10. pp. 83-86.

11. Odintsova G. V., Veiko V. P., Gornyi S. G., Lyong V., Moskvin M. K., Romanov V. V., Shchedrina N. N., Lutoshina D. S., Antipenkova D. A., Kutepova M. S. Fotonika. 2018. Vol. 12. No. 6 (74). pp. 568-575. DOI: $10.22184 / 1993-7296.2018 .12 .6 .568 .575$.
12. Sprovieri J. Part marking options. Assembly. 2014. Vol. 57 (8). pp. $1-7$.

13. Chirkova O. S., Konchus D. A., Sivenkov A. V. Influence of laser marking on the properties of $08 \mathrm{Kh} 18 \mathrm{~N} 10$ steel surface. Metalloobrabotka. 2018. No. 4 (106). pp. 21-27.

14. Bolobov V. I., Shneerson Ya. M., Lapin A. Yu. et al. (2013) Behavior of chromium-nickel alloys, during the process of low-temperature autoclave oxidation of refractory sulfide gold-containing raw materials. Tsvetnye metally. 2013. No. 2. pp. 76-81.

15. Odintsova G., Andreeva Y., Salminen A., Roozbahani H., Lan Cuong V., Yatsuk R., Golubeva V., Romanov V., Veiko V. Investigation of production related impact on the optical properties of color laser marking. Journal of Materials Processing Technology. 2019. Vol. 274. No. 12. 116263. DOI: 10.1016/j.jmatprotec.2019.116263.

16. KonchusD.A., SivenkovA.V.Asurfacestructure formation of stainless steel using a laser. Materials Science Forum. 2020. Vol. 1022 MSF. pp. 112-118. DOI: 10.4028/www.scientific.net/MSF.1022.112.

17. Makhov V. E., Sytko I. I. The measuring accuracy study of the light mark coordinates of laser modules. E3S Web of Conferences. 2020. No. 164. DOI: 10.1051/e3sconf/202016408015.

18. Efimov A. E., Maksarov V. V., Timofeev D. Y. Modeling dynamic processes at stage of formation of parts previously subjected to high-energy laser effects. IOP Conference Series: Materials Science and Engineering. 2018. Iss. 2. Vol. 327. pp. 1-7. DOI: 10.1088/1757-899X/327/2/022026.

19. Gospodarikov A. P., Vykhodtsev Ya. N., Zatsepin M. A. Mathematical modeling of seismic explosion waves impact on rock mass with a working. Journal of Mining Institute. 2017. Vol. 226. pp. 405-411. DOI: 10.25515/pmi.2017.4.405.

20. Schipachev A. M. The choice of an optimal technological process for mechanical treatment of machine components based on structural models. IOP Conference Series: Earth and Environmental Science. 2019. Vol. 378. Iss. 1. pp.1-7. DOI: 10.1088/17551315/378/1/012070.

21. Odintsova G. V. Study and development of the technology of colour laser marking of metals via the method of local oxidation. Dissertation of Cand. Eng. ITMO University. St. Petersburg. 2014. $116 \mathrm{p}$.

22. Veiko V. P., Gornyi S. G., Odintsova G. V. Patrov M. I., Yudin K. V. Forming of multi-colour image on metal surface during its laser oxidation. Izvestiya vysshikh uchebnykh zavedeniy. Priborostroenie. 2011. Vol. 54. No. 2. pp. 47-52.

23. Bavykin O. B., Vyacheslavova O. F. Forming of the minimal surface roughness value for machine components on the base of selection of optimal procedures for dimensional electrochemical treatment. Izvestiya MGTU “MAMI". 2010. No. 2 (10). pp. 103-108.

24. Liang J. Y., Li D. G. Research on the Speed Optimization of Laser Marking. Advanced Materials Research. 2012. Vol. 571 AMR. pp. 411-415. DOI: 10.4028/www.scientific.net/AMR.571.411.

25. Vereshchagin M. N., Tselueva S. N., Tseluev M. Yu. Modification of surface layers of metallic components via impulse laser treatment. Lityo i Metallurgiya. 2020. No. 1. pp. 99-109. DOI:10.21122/1683-6065-2020-1-99-109.

26. Ganzulenko O. Y., Petkova A. P. Simulation and approbation of the marking laser process on metal materials. Journal of Physics: Conference Series. 2021. Iss. 1. Vol. 1753. pp. 1-6. DOI: 10.1088/1742-6596/1753/1/012016

27. Shannon G., Hypsh S. Femtosecond lasers improve processing of metal, plastic parts. Assembly. 2015. Vol. 58 (10). pp. 1-5.

28. Jin Rui Li, Ai Qun Wang, Jian Mei Li, Yu Song Wu. An adaptive image binarization method for laser direct marking data matrix symbols on metal surface. Applied Mechanics and Materials. 2013. Vol. 401-403. pp. 1319-1323. DOI: 10.4028/www.scientific.net/ AMM.401-403.1319.

29. Camillo J. Lasers for marking parts: When the application calls for a high volume of parts to be permanently marked, a laser-based system is the best choice. Assembly. 2016. Vol. 59 (8). pp. 1-4. 